\title{
Disrupting Patriarchal Perceptions of Single-Mother Families: An Analysis of Adolescent Narratives
}

\author{
Carmelita Jacobs \\ https://orcid.org/0000-0001-6344-1522 \\ Stellenbosch University, \\ South Africa \\ carmelitaj32@sun.ac.za
}

\author{
Grant Andrews \\ https://orcid.org/0000-0001-5268-0800 \\ University of the Witwatersrand, \\ South Africa \\ gcandrews@gmail.com
}

\section{Abstract}

Parental educational support plays a significant role in the educational success of learners. Research has emphasised the important role of father involvement in educational achievement; however, little is known about how educational support is understood within marginalised contexts such as female-headed households, especially where fathers are absent or largely uninvolved in the lives of children. This article presents the perspectives of six adolescents in a South African community who reflect on what father involvement means to them in relation to educational support. Semi-structured interviews and a focus group were conducted with the participants to discuss their experiences. We use feminist theory to highlight the informal and non-traditional forms of support that are present in these female-headed households. The data were analysed by means of thematic content analysis. The findings revealed that all the adolescents had complex and deeply personal perspectives on the role a father could play in their lives, and that these views often contrasted with dominant stereotypes of female-headed households as inherently inferior. Although all the adolescents showed a desire for a relationship with a biological father, in some cases the influence of a father was framed as detrimental to the family unit and the educational success of the adolescents. These findings have implications for how schools and educational stakeholders can understand and engage with adolescents and families in female-headed households.

Keywords: parental educational support; adolescents; father involvement; femaleheaded households; feminist theory

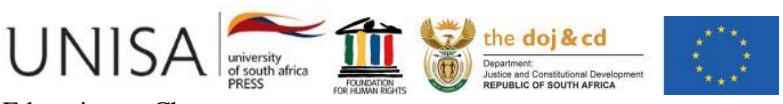

Education as Change 


\section{Introduction}

Father involvement has been a topic of growing scholarly debate both within South Africa and internationally, and researchers have been particularly interested in how a lack of father involvement impacts the educational achievement of children (Kim and Hill 2015; Okeke 2018; Richter and Morrell 2006). The specific contributions that fathers can make have been framed in highly gendered terms that may reflect patriarchal norms (Kim and Hill 2015). Feminist family studies have also shown that families continue to be sites with unequal distribution of power (Allen, Lloyd, and Few 2009), which often privilege those families with present and involved fathers. We seek to disrupt the socially constructed framing of single-mother households as "broken homes" or an "educational disadvantage" (Hampden-Thompson and Galindo 2015).

This article discusses the perspectives of adolescents in single-mother families in a lowincome South African community and how these adolescents discuss the role of father involvement or non-involvement in their educational support. In highlighting the narratives provided by adolescents themselves, we hope to add to the debate of father involvement from a perspective that values the forms of support that mothers in these households offer to their adolescent children, and that challenges patriarchal conceptions devaluing the contributions of women as heads of households. Our article presents findings from a larger qualitative research project that explored parental educational support within six participant families through interviews and a focus group. Through analysing our data, we found that many adolescents expressed a desire for a better relationship with their biological fathers; however, they acknowledged that they received many forms of support often ascribed to fathers from other significant figures in their lives, including their mothers.

\section{Single-Mother Families and Fatherhood in South Africa}

A review of the scholarship shows that ideal family units are often conceived in traditional ways, namely as consisting of a mother, father and child(ren) (see, for example, Freeks 2017; Levin and Currie 2010), the structure commonly known as the nuclear family. However, there is a range of emerging scholarship that is critical of the heterosexist and patriarchal ideological underpinnings of viewing the nuclear family as the norm, with scholars stating that the traditional family "as a naturally caring unit is a fantasy" (Ratele and Nduna 2018, 31). According to these scholars, there are many cases in which the traditional family structure may not be the desired configuration for families, especially in light of factors such as domestic violence, drug abuse and sexual violence exhibited by one or both parents (Ratele and Nduna 2018).

Davin (2016) describes several family configurations that contradict the traditional view of the nuclear family, for example, families headed by grandparents, foster parents and adoptive parents; cross-cultural, multi-religious or same-sex families; and the extended family, where aunts, uncles and cousins are all considered part of the family unit. South Africa also has many child-headed homes, where an older sibling takes care of younger 
siblings in the absence or death of parents, a phenomenon that has been exacerbated by the AIDS epidemic in the country (Shava, Gunhidzirai, and Shava 2016). Additionally, there is the single-parent household, headed by a single mother or a single father. In the South African context, a mother is most often the sole parental figure in single-parent households (Bojuwoye and Sylvester 2014), with 46.4\% of households in South Africa being female-headed (Shung-King et al. 2019).

Female-headed households are often viewed through a deficit perspective because of the absence of a father. This family form is often seen as "income-deprived, vulnerable and inferior" (Chant 2015, 21), and described as an educational disadvantage (Hampden-Thompson and Galindo 2015). Patriarchal discourses are central to conceptions of fathers as necessary components of "good" family structures, and the nuclear family is idealised often due to the supposed superiority of fathers in realms of discipline, protection, leadership and their role as breadwinners (Clowes, Ratele, and Shefer 2013), while mothers are viewed primarily in nurturing and supportive roles. However, researchers have problematised this idealisation of the nuclear family, and demonstrated how lived experiences often contradict the essentialised and valorised roles of fathers (Clowes, Ratele, and Shefer 2013; Ratele and Nduna 2018). Scholars have argued that a major influence on the way family forms are judged is related to global market trends, which determine what is valuable and what is not (Constable 2009). According to Constable (2009), intimate relationships between parent and child, for example parental educational support practices, have become commodities that can be bought, sold, packaged, advertised, consumed or assigned value, which echoes "a global capitalist flow of goods" $(2009,50)$. Applying market norms renders women's labour as less valuable than men's labour, and for this reason the present and involved father is viewed as bringing value to the family. In order to disrupt what is considered valuable parental support in diverse family structures, it is necessary to problematise these discourses that idealise the nuclear family and the father's role, and to think beyond reductive perspectives that seek to commodify parental practices and devalue women's roles.

We use feminist theory to frame our interpretation of the narratives we analyse in this study (Allen 2016). According to Allen, Lloyd, and Few (2009, 4), "an important conceptual tool of a feminist analysis of families is deconstructing a binary notion of agency and structure by recognising that both human actions and social structures are characterised by tensions and ambivalence". In the context of this study, this means that within a structure, such as a female-headed household, single mothers can possess agency despite structural constraints. A feminist perspective can recognise both the structural limitations placed on women and the ways that they are disempowered through patriarchy, as well as recognising and valuing their agency in challenging and navigating the gendered norms within which they operate. An important element of our study is to highlight these tensions and ambivalences present in the narratives of the adolescents as they reflect on father involvement. 
Feminist theory seeks to disrupt patriarchal assumptions of families and encourage a more nuanced understanding that recognises the strengths and forms of support that are present in non-nuclear family structures (Allen 2016; Allen, Lloyd, and Few 2009; Sharp and Weaver 2015). A nuanced view on father involvement encourages scholars to explore traditional ways in which fathers can be involved, as well as broader perspectives on father involvement, such as the value and contributions of social fathers including neighbours, teachers, religious leaders and other males who contribute to the well-being of children and their educational achievement (Van den Berg and Makusha 2018). Additionally, the gendered foundations of idealised concepts of traditional families can be challenged, and the multidimensional roles that mothers and other female figures play in their families can be acknowledged and valued (Jacobs 2019; Jacobs and Daniels 2020).

In light of the important role that educational support from parents can play in the educational achievement of children, and the multiple challenges faced by low-income families in South Africa to provide educational support (Myburgh, Niehaus, and Poggenpoel 2002; Smit and Liebenberg 2003), it is important to consider what support children in these contexts require and how educational support can be rethought within single-mother families. This article explores how adolescents perceive their education as impacted by their emotionally and/or physically absent fathers as they are raised in single-mother households.

Single-mother households are formed due to a variety of circumstances and influences. These could include the death of a parent, divorce, unplanned pregnancy or the choice of the mother to raise her children as a single parent. However, in a report on the state of fatherhood in South Africa, researchers found that "while single motherhood may not necessarily be a choice by some women, co-residency with the biological father is not always the sought outcome" (Ratele and Nduna 2018,30), especially in families where fathers abuse drugs or initiate violence in the family. Ratele and Nduna's (2018) research shows that fathers are generally absent in South African families. Fathers are often stereotyped, both socially and within academic spheres, as being disinterested in being involved and present in their children's lives (Madhavan, Townsend, and Garey 2008; Okeke 2018).

Scholars have highlighted public discourses of a "crisis of fatherhood" that contend that "fathers are vital in providing stability within the family [but] many fathers are no longer successful in fulfilling this role" (Andrew 2016, 37). However, these stereotypes essentialise the father figure and centralise his perceived positive influence within the family unit, and Madhavan, Townsend, and Garey (2008) note that this creates a discourse that mothers are inadequate as parents. South African fatherhoods particularly are conflicted due to the high unemployment rate in South Africa that undermines concepts of masculinity linked to the provider role (Ramphele and Richter 2006), and the horrific rates of gender-based violence in the country, especially intimate partner 
violence (Karim and Baxter 2016), that cast men as threats to the safety of women and children (Andrews 2016, 29).

These dynamics of fatherhood in South Africa contrast with patriarchal conceptions that fathers are necessary for the stability of family units (Mintz 1998). The high rate of single-mother families in the country should be seen as requiring views of parental educational support that are cognisant of context, and that decentre the father in conceptions of supportive family structures, especially in low-income settings such as the one studied in this article where nuclear family units are in the minority (Hall et al. 2018). The adolescents' narratives of parental involvement discussed in this article point to a broader conception of educational support that takes into account the agency of single mothers in providing multiple forms of support to their children. While this does not suggest that these families are ideal or that an additional income earner, childminder or decision maker would not be able to contribute meaningfully to these families, the narratives point to the understanding that the biological father is not the only source of this type of support. In addition, educational support particularly is shown to be multifaceted and to take non-traditional forms that rely on the cultural capital (Yosso 2005) of single mothers, which refers to the types of often-undervalued resources that can be drawn on to overcome adverse circumstances and achieve educational success.

\section{Conceptualising Educational Support and Father Involvement}

Parental educational support refers to the support that parents can offer in terms of promoting their children's self-regulated learning both within the classroom and at home (Kim and Hill 2015; Thomas et al. 2019). This can take the form of providing motivation and guidance, fostering learning strategies and being actively involved in the child's learning. However, as Thomas et al. $(2019,2)$ explain, "research about specific parental practices at home that foster [self-regulated learning] are still scarce". The contributions of all primary caregivers to educational support are important; however, there is a growing body of research that seeks to understand the contributions and practices of fathers in particular (Jeynes 2015; Kim and Hill 2015; Mncanca, Okeke, and Fletcher 2016; Okeke 2018; Richter and Morrell 2006). The concept of father involvement constitutes positive engagement in activities that promote educational opportunities for their children. Makusha, Van den Berg and Lewaks $(2018,74)$ describe father involvement as the "practical, financial or emotional engagement of a father in the life of his children". One of the main factors influencing how father involvement is perceived is the quality of the father-child relationship (Kruk 2010). Thus, educational support as related to father involvement is a broad concept covering multiple ways of caring and being attentive to children that positively impact their education. Educational support is not only seen as the direct interventions of parents into children's studies or schooling, but the multiple home-based practices that research has shown to positively impact educational achievement, including attentiveness, material or financial support, and providing motivation or encouragement (Myburgh, Niehaus, and Poggenpoel 2002; Smit and Liebenberg 2003). The participants in the 
study were asked to consider their education and the impact that their absent fathers have on their educational success, but the answers they provided were frequently based on emotional needs, concepts of family stability and the idea that a nuclear family structure would be beneficial to them.

Research on parent involvement has shown that although there are multiple ways of parenting and demonstrating support, the adolescent's perception of parenting behaviours plays an important role, especially because the "family, and particularly the parent-adolescent relationship, provides one of the most important social contexts for adolescent development" (Kerpelman, Eryigit, and Stephens 2008, 1000). In other words, it is important to recognise that "children actively process and filter what parents do and say" (You and Nguyen 2011, 555). For this reason, accounting for adolescents' perspectives of father involvement is a significant component in understanding which aspects of father involvement are most important (Jeynes 2015).

In contrast to other social science research, this research does not treat the absence of a father as necessarily indicating an absence or lack of educational support in the lives of children. Instead, educational support is conceptualised as comprising the behaviours of people within and outside of the family unit. Thus, exploring how adolescents from these female-headed families perceive father figures, especially where they might experience a strong level of educational support in informal or non-traditional ways, can serve to challenge patriarchal conceptions of female-headed households as inherently deficient, and can offer insight into how gendered roles interact with concepts of educational support in these contexts.

\section{Research Context and Methodology}

The data and findings presented in this article were part of a larger study on educational support within female-headed households in a low socioeconomic status (SES) community in South Africa (see Jacobs 2019). This article specifically presents the findings on how adolescents perceived their fathers or father figures in ways that challenge patriarchal conceptions that fathers are central to family stability, adolescent development or educational success. The research was conducted in a township community situated in Cape Town, in the Western Cape province of South Africa. This community can be classified as low SES, as residents overwhelmingly are faced with unemployment, poverty, gangsterism and violence in families. Residents of this township live in small brick homes, in backyard dwellings such as wooden homes (known locally as Wendy houses), and in corrugated iron shacks. The population for this study comprised adolescents between the ages of 14 and 18 years old, who were enrolled in a local high school and had been raised by a single mother for most of their lives. This also included families where the mother had remarried or lived with a partner, but where the adolescent had still been part of a single-mother family for most of their lives. 
This research was undertaken with the understanding that reality is subjective and that it can have multiple meanings; the focus was on the participants' stories or representations of their lives and experiences. This belief is aligned with the social constructivist paradigm (Creswell and Poth 2016; Denzin and Lincoln 2011). This paradigm recognises that reality is socially and personally constructed and the subject is actively involved in the process of meaning making (Creswell and Poth 2016). In addition, the researchers took a feminist approach in working with the families and in discussing the findings of the research. Feminist theory encourages researchers to "[focus] on the experiences of women in natural social settings" where the aim of research is to "make women visible, raise their consciousness and empower them" (Gelling 2013, 6). We aimed to gather our data and frame our discussion in ways that recognise the value of the mothers in their family units. The methods of data collection included individual interviews with the participants (which included single mothers and their adolescent children) and a focus group discussion with the adolescents. In this article we focus on the data that related to the adolescents' narratives of father involvement, as these speak more directly to lived experiences of educational support.

The data collected were analysed by means of thematic content analysis. Ethical principles guiding this study included seeking informed consent and assent, respecting confidentiality and maintaining unbiased interactions with the participants and the data. We hope that this research will impact the way single-mother families are discussed in research, and that researchers will resist simplistic and gendered deficit concepts of these families. In addition, we hope that the types of educational support found in these settings can be acknowledged and engaged meaningfully by educators, teacher trainers, policymakers and mental health professionals such as educational psychologists, for the benefit of single mothers and their children.

With the exception of one family, all families identified as being of the coloured "race", and the community under discussion is considered a traditionally Afrikaans-speaking coloured community. Three female and three male adolescents participated in the study. Most of the participants were in Grade 9, and their average age was 15. All the participants were attending high schools outside the community, as there were no local high schools in the community. One participant attended a school far from the community and travelled to school by train, as his mother did not want him to attend the nearby schools. The other participants walked to their various high schools, which were all between two and five kilometres from their homes. Pseudonyms are used for all participants in the findings and discussion sections below. Participants' responses that were given in Afrikaans were translated into English by the researchers for use in this article.

The term "coloured" is a racial category in South Africa that was used in apartheid legislation to refer mainly, but not exclusively, to people of "mixed-race", indigenous South African (Khoi or San), or Malay descent. While it is contested, it still carries wide currency in the country. 


\section{Findings}

The adolescents' narratives reflected the need for a "present" father, which initially seemed to conform to common conceptions of fathers as central in family structures, adolescent development and educational support. When asked about their needs for educational support, most of the adolescent participants described the lack of a father's support as a significant need. Then, when asked how they wanted their fathers to be involved, the responses appeared to focus on basic needs related to feeling cared for and acknowledged. Although the male adolescent participants were aware of the support a father could provide, they deemed the support of their mother good enough. It seemed as though the absence of a father was less significant and less emotionally affecting for the male participants. The female participants, on the other hand, became noticeably emotional when asked about their fathers' lack of involvement, indicating a sense of sadness and loss that they did not have a relationship with their fathers. In our analysis, three categories of needs emerged from the six participants, namely the need for emotional support, the need for financial support and the need for their existence to be acknowledged.

\section{Adolescents' Narratives on their Needs for a Father's Support}

\section{Emotional Support}

The data show that the participants' general perceptions of fatherhood are informed by the conventional views of what a father's role should be, namely, to be physically present in the lives of his children and female partner and supporting them financially and emotionally. The male adolescents framed emotional support in terms of needing a man's perspective on "manly issues". Despite all of them describing their mothers as involved parents who are caring and interested in their challenges in life, they all seemed to have internalised the view that a father would have performed this role better than their mothers could.

The gender of the parent seemed to be viewed by the adolescents as more suited to specific topics or issues. Calvin (male, age 17) fantasised about how it would have been to have a father with whom he could "have man-to-man talks and hang out sometimes ... talk, have a relationship with him and get to know each other ... talk about girl issues". Similarly, Tommy (male, age 15) stated that he could speak to his mother about everything, except "girls". However, even though the adolescent males spoke about the role their fathers could have played in offering relationship guidance, all of them emphasised that their fathers' absence did not affect them that much, and this was interpreted by the researchers as fear that expressing a longing for their fathers would be a form of betrayal to their mothers. All of them reiterated an idea expressed by Tommy: "In my eyes my mother is mother and father to me. I don't really worry about my father because he never cared for us." 
The female participants framed emotional support from their fathers as a need for care and love from them. One participant stated:

I wish I also had the support of my father. He should have been there for me all these years. He should have cared about me, helped me, helped my mom with me and so on. (Therren, female, age 15)

Participants seemed to believe that in two-parent families more love and support are available to children. This is evident in Palesa's narrative where she compared her family with that of her friends' two-parent families and viewed her own family as different from the norm and as deficient. She explains:

Sometimes, when we sit with our group of friends ... each one of my friends stays with their parents. Their mother and their father. And that doesn't feel right to me. Without my father it feels like I'm not making any progress with my life. (Palesa, female, age 15)

Our analysis of the participants' narratives indicates that these young girls subscribed to the social construction of single-mother families being broken and incomplete. They spoke with a sense of sadness and longing when considering the need for a father's emotional support. While these discussions were framed through questions of educational support, it is clear that adolescents had very strong emotional needs that they felt stood in the way of their educational achievement; as Palesa states, she was "not making any progress with [her] life". The gendered element is significant as girl participants seemed to express a greater need for father involvement, yet longitudinal studies have shown that "there is little difference in how father involvement affects adolescent boys versus girls" (Carlson 2006, 149) in educational or behavioural outcomes. The way that boys and girls respond to a lack of support from their fathers might indicate the way that the adolescents have been socialised by different gender roles and expectations; research has shown that "males are socialized to value independence and autonomy, [and] females are often socialized in ways that reinforce the significance of nurturant and affiliative bonds with others" (Cooper 2009, 497). These considerations of gender socialisation are significant in this study, both in the way that male and female adolescents respond to absent fathers, and in the way that the type of support from mothers is valued differently than the support from fathers.

\section{Financial Support}

The absent father was held responsible for the lack of material resources within the family. The adolescent participants' views reflect a belief that if a male parent were present, their mother would not struggle financially; they would not need to sacrifice as much as there would be money for material resources. Most of the participants stated that their fathers never made child maintenance payments. Some of the mothers noted that they had even taken the fathers to court, however this was not always successful. As a result, many of the participants' mothers depended on social grants from the 
government and intermittent cleaning work. One participant pointed out that she believed that if they were a two-parent family she would have been able to have things such as clothes and other items her teenage friends had:

For me it could have been different. Things I couldn't get, I could have had ... if it had been both parents. (Palesa, age 16)

However, the other participants referred to educational needs that money from their fathers could have helped with, such as school fees and books (Calvin, age 17), and basic needs such as food and toiletries (Tommy and Therren, age 15). These narratives demonstrate the association of the absence of the father with financial instability, and the idea that the father's involvement would lead to less worry for the family about making ends meet.

The narratives demonstrate that financial difficulties are a significant stressor for adolescents and impact their access to educational resources, as well as placing the families in precarious positions affecting the adolescents' educational achievement. However, adolescents also shared narratives of unemployed fathers, such as in Palesa's and Nelly's narratives, and fathers who had refused to financially support their children. These idealised views of fathers as potential financial providers seem to be linked to stereotypes of men as better providers (Richter and Morrell 2006), and do not reflect the reality that the mothers were much more likely to be employed or to financially provide for their children in these families.

\section{Showing an Interest/Acknowledging their Existence}

Although the adolescents attributed the families' financial struggles to absent fathers, they insisted that financial security was not the main reason they wanted a present father. The findings indicated that they wanted their fathers to acknowledge their existence. Many of the participants used the words "not interested" and feeling "ignored" in describing how they perceived their fathers' absence or lack of involvement. Tommy (male, age 15) stated: "He used to call at one time, and then suddenly he stopped calling. He isn't interested anymore." This theme was especially dominant during the focus group discussion. The adolescents emphasised that their need for a father's presence in their lives was not for material security; rather, it was about maintaining or fostering a relationship, as well as knowing that their fathers cared and that they were interested in their lives and in what they were doing at school. This is especially evident in the way Mikyle (male, age 15) described support as

communicating with your child about school, and getting to know you, and getting to know your father better. That would make me feel supported, and know he isn't ignoring me. 


\section{Adolescents' Narratives on the Problem of the Abusive Father: "But What I Actually Want Is for Him to Leave Our House"}

In contrast to the narratives of desiring greater acknowledgement and presence of fathers, especially biological fathers, there were aspects of the narratives that demonstrated the father as a negative influence and a deleterious factor in the lives of the adolescents. Although these adolescents were being raised by single mothers, in two cases abusive fathers continued to affect the families as they lived in the same community and were still in limited contact. This section explores two mother-daughter dyads' narratives of living with an abusive father and partner. These narratives also illustrate how these fathers are physically present but emotionally absent from these adolescents' lives.

Nelly grew up in a single-parent home for most of her life; however, she had a stepfather for a few years. He was a drug abuser whose violent acts towards his family were precipitated by his drug use. At the time of the interview, her mother Mandy had divorced Nelly's stepfather, and although he was still living in a separate dwelling on the property, he was no longer living in the home as part of the family unit. Nelly described how she often had to defend her mother: "I challenged him ... many times." She narrated that when she was present her stepfather would argue and shout, but when Nelly was not home, he would become violent and start physically striking her mother. These experiences caused Nelly to internalise a belief that she did not want to be like her mother, and it frustrated her that her mother stayed with her stepfather and dismissed his violent behaviour.

Palesa's narrative shows similarities with Nelly's. Palesa's father, after having been absent for many years, moved in with their family unit in the three years prior to the interview. However, even though he lived with them, Palesa's mother still perceived herself as a single mother, as she was not receiving any financial or emotional support from Palesa's father. Instead, he was considered to be a burden, especially since Palesa's mother twice had to arrange his release from jail. Palesa and her mother explicitly stated that they wished he would leave.

Palesa's narrative demonstrates the harsh effects that the negative experience of a present but abusive father can have. She described how, when her father had been drinking, he would disrupt the family's sleep at night and cause discord in the home. Thoughts of the previous night's chaos would then distract her the next day at school:

Every time my father is drunk and he shouts at me, I think about it at school. He is drunk during the week and when he gets home he carries on. Then we cannot sleep because they are fighting. I have to get up early in the morning to go to school, but I cannot get up and I'm late for school. Because I couldn't sleep peacefully because he carried on and then I think about it at school. When he comes into the house and he is drunk, then I cannot concentrate any further. There's a racket. He swears the whole time. 
Palesa also described how she would never ask her father for help. She recounted an instance when he bought her something she wanted and then later when he became angry, he destroyed the item. Palesa also stated that her father often reminded her of any help that she requested from him, and that he did not seem to offer assistance freely:

I actually don't often ask them for anything, because sometimes when I ask my father for something, he buys it for me, but then afterwards he takes it back and tears it up. I never ask my father for help. But then again, when I ask him for help, he talks about it all the time.

During this conversation, Palesa reflected fondly on the time they lived as a singlemother family without the presence of her father:

This year he has had a lot of my mother's support. But what I actually want is for him to leave our house. I really liked it when it was just my sister and my mother. It was much better.

Palesa's summation that it was much better when they were just a single-mother family challenges the image of the single-mother family being disadvantageous for children. Instead, this narrative implies that some single-mother families, despite the adversity they experience, could be preferred by the children involved. Indeed, in a country with one of the highest rates of violence in the world, overwhelmingly committed by men, and where gender-based violence is a pervasive and everyday reality (Graaf and Heinecken 2017), a large number of fathers might be viewed with similar fear or resentment by their children and female partners.

Our analysis of the findings shows that the participants' longing for a present father was largely based on the social construction of the role a father figure could play, such as the provider role or the idea of a father as the head of a household (Richter and Morrell 2006). However, in reality, the physically present father was not always a positive influence for the family, and fathers who were present for periods of the adolescents' lives were often emotionally distant, thus challenging essentialist notions of the role of fathers. Many of the adolescents' narratives, even those that longed for the stereotypical influence of a father, acknowledged that mothers were fulfilling aspects of these roles in their families and providing multiple forms of emotional, material and educational support. The narratives demonstrate complex ideas of absent fathers imagined as potentially positive influences by adolescents who, in the cases where they were present, seemed to have strong negative effects on educational achievement and the stability of the family unit.

\section{Absent Father Does Not Mean an Absence of Support from Male Figures}

The adolescents' narratives also revealed that although they lacked the support of a biological father, they received support from other male figures in their family and in their community. Grandfathers, brothers, cousins, teachers and neighbours all seemed 
to play significant roles in providing educational and other forms of support to the adolescents. Calvin described how his brother, who was older than Calvin by 10 years, "was like a father to me ... he supported me all the way". For Tommy, his grandfather played a significant role in his life. Tommy shared: "If there is something I don't understand [in schoolwork], then I ask my grandfather. He always says it doesn't matter how hard it is, I can still ask for help."

Extended family members such as cousins or uncles also served as role models for the adolescents, seemingly acting as surrogate fathers to them. These influential male figures also provided forms of the indirect educational support that adolescents often find beneficial (Bhargava and Witherspoon 2015). Calvin and Therren spoke of family members who were attending university, and how this inspired them to continue their own education. Interestingly, these surrogate father figures were not always male, as female family or community members such as aunts and neighbours were also providers of emotional, material and educational support in many of the adolescents' narratives. The longing for the father figure displayed by all the adolescents at times in their narratives was disrupted by their own narratives of support from others, and through the negative role that present fathers at times played in their lives.

\section{Discussion}

It is widely argued and believed that an absent father is harmful to the well-being and educational success of a child (Carlson 2006; Freeks 2017; Levin and Currie 2010). However, as demonstrated in the research of Freeks (2017), studies focusing on the detrimental effects of fatherlessness often rely on stereotypical and essentialist views of masculinity and fatherhood, which might perpetuate patriarchal conceptions that dismiss or invisibilise the forms of support offered by women, and locate agency, stability and familial harmony solely as a function of the male figure. These arguments are abstracted from the reality of a country where the vast majority of families do not fit the nuclear structure (Hall et al. 2018), and where $46.4 \%$ of households are femaleheaded (Shung-King et al. 2019). We contend that these arguments lamenting fatherlessness as a central reason for educational and social ills are counterproductive, and that South African researchers can better serve their communities by confronting the realities of non-nuclear family structures and by challenging deficit discourses.

In this article, narratives of the uninvolved, disinterested and unsupportive absent father figure emerged. The adolescent participants' need for a father's support appears to be based on an essentialist perspective regarding the social role a father "should" play. In other words, the participants seemed to reflect the view that a father should be the provider and protector of the home, and that boys specifically rely on a father to achieve a masculine identity (Silverstein and Auerbach 1999), while girls rely on fathers for emotional connection and love (Cooper 2009). However, essentialising the father is often based on the assumption that a mother's care is inadequate (Madhavan, Townsend, and Garey 2008), and it centralises masculine roles and male agency, thus devaluing and invisibilising women's contributions within the family, which might extend to non- 
traditional gender roles, including being the head of the household. In this study, the adolescent participants often voiced how well their mothers supported them, yet they still seemed to yearn for the support of a father. This might reflect how they have been socialised by a dominant culture that favours an essentialist and patriarchal perspective of the father (Richter and Morrell 2006).

An essentialist perspective also misrecognises the potential for other significant adults in an adolescent's life who step into and fulfil the role of fatherhood (Madhavan, Townsend, and Garey 2008). In this study, the participants did not necessarily need their fathers to be physically present in their lives; rather, they sought support in the form of interest, care and guidance from adult role models, yet, when they compared themselves with other nuclear families, seemed to deem their family unit "deficient". Furthermore, the term "fatherhood" should allow for an elastic definition, which includes adults living in and around the family (Madhavan, Townsend, and Garey 2008) who support children in these families, including role models who are female or nonbinary in their gender identity. This study illustrates how different people, such as a grandparent, teacher, neighbour or leaders at church, can perform the social role traditionally assigned to fathers, and that a father's absence does not necessarily mean the absence of support, as is often assumed in social science research (see Freeks 2017) and in social conceptions of fatherhood in schools, communities and at times even by the members of singlemother families.

However, although notions of the essentialised father figure emerged as a common thread in the interviews with the adolescents, researchers should be cautious not to uncritically dismiss such ideas in favour of the single mother as "wealthy" in terms of various forms of cultural capital (Yosso 2005), and should take note of the valid and deep feelings that these children feel around their absent fathers. Mental health practitioners could offer support by recognising the feelings of abandonment, longing and sadness that some adolescents voiced around their absent fathers, and find strategies to allow children to feel loved, worthwhile and important in light of their voiced sense of loss around father figures. The data show that even when children realised that male figures were negative influences in their families, the bond that they felt with absent parents was still strong. This essentialised view of fathers should not be dismissed or discounted, and should instead be incorporated into other forms of support for these adolescents, such as recognising the role that other adult figures, siblings or community members could play as additional support figures in the child's life.

It should also not be taken for granted that these single mothers are capable of fulfilling all roles for their children, and educational support strategies from schools and mental health practitioners should simultaneously recognise the types of support mothers can offer while empowering them and implementing interventions that can meet the needs of adolescents in low SES contexts in South Africa. The mothers who participated in the study often voiced feelings connected to struggling and being overwhelmed, which 
should be recognised as signalling a significant need for greater extra-familial support while not negating the roles that these mothers currently play.

The context of the study was the single-mother household, a type of family structure that is common both locally and internationally. The traditional family consisting of two parents of the opposite sex is not the norm in many contexts, including South Africa (Bojuwoye and Sylvester 2014; Shung-King et al. 2019), and in addition, countries such as South Africa show staggering rates of domestic violence, sexual abuse and emotional or physical absenteeism linked to male figures, creating significant trauma for women and children including some of the participants in this study. These realities and the lived experiences of many people call into question the status of the traditional family as necessarily being an ideal family structure in all cases, and challenge the essentialist view of fathers as providing stability and being a necessary component for healthy development and educational success within family units.

\section{Conclusion}

This article presented the narratives of adolescents and how they perceive father involvement. The adolescents voiced their wish for their fathers to be more involved in their lives, yet often associated their needs for father involvement with stereotypical gendered concepts that their fathers were unable or unwilling to provide, or that were in some ways being provided by mothers and other significant figures in their lives. It was clear that participants, such as Nelly and Palesa, showed a clear preference for life without the negative influence of a father figure. In their cases, the single-mother family was seen to be more educationally and emotionally advantageous than might have been expected based on conventional discourses of the idealised traditional family. Our argument in this article is that any family structure, whether nuclear or non-nuclear, can have forms of successful support for children, and particularly in low SES communities in the South African context, it should not be automatically assumed that the presence of the father will lead to better forms of support or that single-mother families are somehow inherently deficient. Our article challenges the notion that fathers are necessarily better providers of particular forms of support, and cautions against the essentialist patriarchal views that would fail to recognise the forms of capital that mothers employ in their child-rearing.

The data have demonstrated many points that would be fruitful for further research. First, the patriarchal conceptions of father involvement might be very different in different family structures, such as single-father households or families with same-sex parents. Future research could explore these family structures in more detail in light of the types of narratives voiced by the participants in this study. Additionally, while this article solely focused on how the adolescents perceived father involvement, the findings of the categories of needs voiced by the adolescents could be used to develop strategies for school-based educational support and for interventions in assisting educational support in single-mother families. Adolescents voiced the need for emotional support, financial support and for the acknowledgement of their existence from absent fathers. 
While these types of support might not be forthcoming from fathers themselves, those working in mental health services, the education sector and in social services could be cognisant of these needs in designing models of educational support for children from low SES communities in South Africa.

\section{References}

Allen, K. R. 2016. "Feminist Theory in Family Studies: History, Reflection, and Critique". Journal of Family Theory and Review 8 (2): 207-24. https://doi.org/10.1111/jftr.12133.

Allen, K. R., S. A. Lloyd, and A. L. Few. 2009. "Reclaiming Feminist Theory, Method, and Praxis for Family Studies”. In Handbook of Feminist Family Studies, edited by S. A. Lloyd, A. L. Few and K. R. Allen, 3-17. Thousand Oaks, CA: Sage Publications. https://doi.org/10.4135/9781412982801.n1.

Andrews, G. 2016. "Representations of Fatherhood and Paternal Narrative Power in South African English Literature”. PhD diss., University of the Western Cape. http://etd.uwc.ac.za/xmlui/handle/11394/4848.

Bhargava, S., and D. P. Witherspoon. 2015. "Parental Involvement across Middle and High School: Exploring Contributions of Individual and Neighborhood Characteristics". Journal of Youth and Adolescence 44 (9): 1702-19. https://doi.org/10.1007/s10964-015-0334-9.

Bojuwoye, O., and F. Sylvester. 2014. "Subjective Well-Being of Adolescent Boys Living in Single-Mother Households in a Cape Town Suburb, South Africa”. Mediterranean Journal of Social Sciences 5 (23): 2017-25. https://doi.org/10.5901/mjss.2014.v5n23p2017.

Carlson, M. J. 2006. "Family Structure, Father Involvement, and Adolescent Behavioral Outcomes". Journal of Marriage and Family 68 (1): 137-54. https://doi.org/10.1111/j.1741-3737.2006.00239.x.

Chant, S. 2015. "Female Household Headship as an Asset? Interrogating the Intersections of Urbanisation, Gender, and Domestic Transformations". In Gender, Asset Accumulation and Just Cities: Pathways to Transformation, edited by C. O. Moser, 33-51. London: Routledge.

Clowes, L., K. Ratele, and T. Shefer. 2013. "Who Needs a Father? South African Men Reflect on Being Fathered”. Journal of Gender Studies 22 (3): 255-67. https://doi.org/10.1080/09589236.2012.708823.

Constable, N. 2009. “The Commodification of Intimacy: Marriage, Sex, and Reproductive Labor”. Annual Review of Anthropology 38: 49-64. https://doi.org/10.1146/annurev.anthro.37.081407.085133.

Cooper, S. M. 2009. “Associations between Father-Daughter Relationship Quality and the Academic Engagement of African American Adolescent Girls: Self-Esteem as a Mediator?” Journal of Black Psychology 35 (4): 495-516. https://doi.org/10.1177/0095798409339185. 
Creswell, J. W., and C. N. Poth. 2016. Qualitative Inquiry and Research Design: Choosing among Five Approaches. Thousand Oaks, CA: Sage Publications.

Davin, R. 2016. “Teaching Foundation Phase Learners about Social Wellbeing”. In Teaching Life Skills in the Foundation Phase, edited by M. Naudé and C. Meier, 328-30. Pretoria: Van Schaik.

Denzin, N. K., and Y. S. Lincoln, eds. 2011. The Sage Handbook of Qualitative Research. Thousand Oaks, CA: Sage Publications.

Freeks, F. 2017. "Responding to the Challenge of Father Absence and Fatherlessness in the South African Context: A Case Study Involving Concerned Fathers from the North West Province". Stellenbosch Theological Journal 3 (1): 89-113. https://doi.org/10.17570/stj.2017.v3n1.a05.

Gelling, L. 2013. “A Feminist Approach to Research”. Nurse Researcher 21 (1): 6-7. https://doi.org/10.7748/nr2013.09.21.1.6.s2.

Graaff, K., and L. Heinecken. 2017. "Masculinities and Gender-Based Violence in South Africa: A Study of a Masculinities-Focused Intervention Programme". Development Southern Africa 34 (5): 622-34. https://doi.org/10.1080/0376835X.2017.1334537.

Hall, K., L. Richter, Z. Mokomane, and L. Lake, eds. 2018. South African Child Gauge 2018. Cape Town: Children's Institute, University of Cape Town. Accessed March 28, 2021. http://www.ci.uct.ac.za/ci/child-gauge/2018.

Hampden-Thompson, G., and C. Galindo. 2015. "Family Structure Instability and the Educational Persistence of Young People in England". British Educational Research Journal 41 (5): 749-66. https://doi.org/10.1002/berj.3179.

Jacobs, C. 2019. "Parental Educational Support for Adolescents in Single-Mother Families of a Low-Income Community". PhD diss., Stellenbosch University. http://hdl.handle.net/10019.1/107230.

Jacobs, C., and D. Daniels. 2020. “Their Capital Has Value, Too: Exploring Parental Educational Support in Low-Socioeconomic Single-Mother Families”. Journal of Education 80: 160-75. https://doi.org/10.17159/2520-9868/i80a09.

Jeynes, W. H. 2015. “A Meta-Analysis: The Relationship between Father Involvement and Student Academic Achievement”. Urban Education 50 (4): 387-423. https://doi.org/10.1177/0042085914525789.

Karim, Q. A., and C. Baxter. 2016. "The Dual Burden of Gender-Based Violence and HIV in Adolescent Girls and Young Women in South Africa". SAMJ: South African Medical Journal 106 (12): 1151-53. https://doi.org/10.7196/SAMJ.2016.V106I12.12126. 
Kerpelman, J. L., S. Eryigit, and C. J. Stephens. 2008. “African American Adolescents' Future Education Orientation: Associations with Self-Efficacy, Ethnic Identity, and Perceived Parental Support”. Journal of Youth and Adolescence 37 (8): 997-1008. https://doi.org/10.1007/s10964-007-9201-7.

Kim, S. W., and N. E. Hill. 2015. "Including Fathers in the Picture: A Meta-Analysis of Parental Involvement and Students' Academic Achievement”. Journal of Educational Psychology 107 (4): 919-34. https://doi.org/10.1037/edu0000023.

Kruk, E. 2010. "Parental and Social Institutional Responsibilities to Children's Needs in the Divorce Transition: Fathers' Perspectives”. The Journal of Men's Studies 18 (2): 159-78. https://doi.org/10.3149/jms.1802.159.

Levin, K. A., and C. Currie. 2010. "Family Structure, Mother-Child Communication, FatherChild Communication, and Adolescent Life Satisfaction: A Cross-Sectional Multilevel Analysis". Health Education 110 (3): 152-68. https://doi.org/10.1108/09654281011038831.

Madhavan, S., N. W. Townsend, and A. I. Garey. 2008. “"Absent Breadwinners': Father-Child Connections and Paternal Support in Rural South Africa". Journal of Southern African Studies 34 (3): 647-63. https://doi.org/10.1080/03057070802259902.

Makusha, T., W. van den Berg, and A. Lewaks, eds. 2018. “Glossary”. In State of South Africa's Fathers Report 2018, 74. Johannesburg: Sonke Gender Justice and Human Sciences Research Council.

Mintz, S. 1998. "From Patriarchy to Androgyny and Other Myths: Placing Men's Family Roles in Historical Perspective". In Men in Families: When Do They Get Involved? What Difference Does It Make?, edited by A. Booth and A. C. Crouter, 3-30. Mahwah, NJ: Lawrence Erlbaum.

Mncanca, M., C. I. O. Okeke, and R. Fletcher. 2016. "Black Fathers' Participation in Early Childhood Development in South Africa: What Do We Know?" Journal of Social Sciences 46 (3): 202-13. https://doi.org/10.1080/09718923.2016.11893528.

Myburgh, C. P. H., L. Niehaus, and M. Poggenpoel. 2002. "Showing the Work Ethics of South African Black Adolescents Is Determined by Parent Involvement, Their Time Concept, and Efficacy". Education 122 (3): 531-57.

Okeke, C. I. O. 2018. “Crises Impacting South African Men's Participation in Early SocioEducation Development of Children and Possible Useful Interventions". South African Journal of Psychology 48 (4): 476-87. https://doi.org/10.1177/0081246317729572.

Ramphele, M., and L. Richter. 2006. "Migrancy, Family Dissolution and Fatherhood". In Baba: Men and Fatherhood in South Africa, edited by L. Richter and R. Morrell, 73-81. Cape Town: HSRC Press. 
Ratele, K., and M. Nduna. 2018. "An Overview of Fatherhood in South Africa”. In State of South Africa's Fathers Report 2018, edited by W. van den Berg and T. Makusha, 29-46. Johannesburg: Sonke Gender Justice and Human Sciences Research Council.

Richter, L., and R. Morrell, eds. 2006. Baba: Men and Fatherhood in South Africa. Cape Town: HSRC Press.

Sharp, E. A., and S. E. Weaver. 2015. "Feeling Like Feminist Frauds: Theorizing Feminist Accountability in Feminist Family Studies Research in a Neoliberal, Postfeminist Context”. Journal of Family Theory and Review 7 (3): 299-320. https://doi.org/10.1111/jftr.12080.

Shava, G., C. Gunhidzirai, and E. Shava. 2016. "Exploring the Experiences of Young Adults Emerging from Child-Headed Households in Alice, South Africa". Journal of Human Ecology 55 (1): 92-103. https://doi.org/10.1080/09709274.2016.11907013.

Shung-King, M., L. Lake, D. Sanders, and M. Hendricks, eds. 2019. South African Child Gauge 2019. Cape Town: Children's Institute, University of Cape Town. Accessed March 30, 2021. http://www.ci.uct.ac.za/cg-2019-child-and-adolescent-health.

Silverstein, L. B., and C. F. Auerbach. 1999. "Deconstructing the Essential Father". American Psychologist 54 (6): 397-407. https://doi.org/10.1037/0003-066X.54.6.397.

Smit, A. G., and L. Liebenberg. 2003. "Understanding the Dynamics of Parent Involvement in Schooling within the Poverty Context". South African Journal of Education 23 (2): 1-5.

Thomas, V., J. Muls, F. De Backer, and K. Lombaerts. 2019. "Exploring Self-Regulated Learning during Middle School: Views of Parents and Students on Parents' Educational Support at Home". Journal of Family Studies 1-19. https://doi.org/10.1080/13229400.2018.1562359.

Van den Berg, W., and T. Makusha. 2018. Introduction to State of South Africa's Fathers 2018, edited by W. van den Berg and T. Makusha, 5-10. Johannesburg: Sonke Gender Justice and Human Sciences Research Council.

Yosso, T. J. 2005. "Whose Culture Has Capital? A Critical Race Theory Discussion of Community Cultural Wealth". Race Ethnicity and Education 8 (1): 69-91. https://doi.org/10.1080/1361332052000341006.

You, S., and J. T. Nguyen. 2011. 'Parents' Involvement in Adolescents' Schooling: A Multidimensional Conceptualisation and Mediational Model". Educational Psychology 31 (5): 547-58. https://doi.org/10.1080/01443410.2011.577734. 